УДК 338.462

\title{
ИННОВАЦИОННЫЙ ПОДХОД К ОСВОЕНИЮ МИНЕРАЛЬНО-СЫРЬЕВОГО ПОТЕНЦИАЛА АРКТИЧЕСКОЙ ЗОНЫ РФ
}

\author{
А.Е.ЧЕРЕПОВИЦЫН ${ }^{1}$, С.А.ЛИПИНА ${ }^{2}$, О.О.ЕВСЕЕВА ${ }^{1}$ \\ ${ }_{1}^{1}$ Санкт-Петербургский горный университет, Санкт-Петербург, Россия \\ ${ }^{2}$ Всероссийская академия внешней торговли Минэкономразвития России, Москва, Россия
}

\begin{abstract}
Комплексное освоение минерально-сырьевого потенциала Арктических регионов России представляет собой сложную стратегическую задачу, требующую применения современных методов планирования пространственного развития территорий. Одним из таких методов является организация кластерных образований как эффективного инструмента реализации инновационной политики. Консолидируя усилия множества участников, диверсифицированные территориальные кластеры становятся основными точками роста, мультипликативный эффект внугри которых оказывает положительное влияние как на экономику региона, так и страны в целом.

Высокий уровень риска и значительный объем затрат арктических сырьевых проектов обуславливает невозможность их реализации простой аккумуляцией производственных и финансовых ресурсов, ввиду чего возникает необходимость моделирования гибких территориально-производственных систем на принципах интеграции. В статье проанализированы предпосылки формирования кластерных образований на базе ресурсного потенциала опорных зон Российской Арктики, выявлены основные ожидаемые эффекты от создания инновационных сырьевых арктических кластеров. В ходе исследования была обоснована целесообразность применения механизмов интеграции при освоении запасов углеводородов в технически сложных условиях Крайнего Севера. Проведенный стратегический анализ трех арктических нефтегазовых проектов, реализуемых в настоящий момент на принципах кластеризации, - «Новый Порт», «Мессояха», «Ямал СПГ», позволил сделать вывод о наличии достаточного объема внешних эффектов проектов, таких как создание условий для инновационного развития смежных отраслей, формирование высокотехнологичного инфраструктурного каркаса в регионе, накопление опыта в области реализации арктических проектов, диверсификацию экспорта углеводородов.
\end{abstract}

Ключевые слова: Арктика; минерально-сырьевой потенциал; кластеры; нефтегазовые проекты; СПГ

Как цитировать эту статью: Череповицын А.Е. Инновационный подход к освоению минеральносырьевого потенциала Арктической зоны РФ / А.Е.Череповицын, С.А.Липина, О.О.Евсеева // Записки Горного институга. 2018. Т. 232. С. 438-444. DOI: 10.31897/PMI.2018.4.438

Введение. Основным инструментом достижения комплексного развития российской экономики и повышения качества жизни населения в отдаленных северных районах является проведение активной инновационной политики в Арктических регионах, направленной на модернизацию и рост инновационной активности хозяйствующих субъектов. Заметное место в современной инновационной политике занимают территориальные инновационно-технологические промышленные кластеры, формирование и развитие которых должно способствовать развитию конкурентной среды и более полному использованию потенциала взаимодействия государства и бизнеса, в том числе и в социально-экономической сфере [1].

Ключевой особенностью кластерного подхода в отличие от традиционного отраслевого подхода является его ориентация на перегруппировку производительных сил и факторов производства, что приводит к росту совокупной капитализации территории [16]. Кластеры, стараясь максимизировать эффективность своего развития за счет факторов внутренней среды, стимулируют создание своеобразного регионального каркаса, который задает вектор развития различных отраслей экономики и в конечном итоге выступает единицей территориального управления.

Важным аспектом процесса кластеризации является рыночный механизм, проявляющийся в создании высокой внутренней конкуренции, которая выступает основной движущей силой эффективной деятельности кластера [13]. Конкурентная борьба стимулирует каждого участника к постоянному совершенствованию своих преимуществ путем внедрения различных нововведений (технологических, организационных и маркетинговых), что приводит к более активному инновационному развитию кластера. Мировой опыт внедрения кластерного подхода свидетельствует о том, что именно кластеры позволяют формировать ключевые компетенции, прогресс которых служит основой конкурентоспособности регионов в долгосрочной перспективе [14]. 
Постановка проблемы. Основу перспективного экономического развития Арктической зоны составляет богатая минерально-сырьевая база различных видов полезных ископаемых [12]. В Арктической зоне РФ, на долю которой приходится болльшая часть Арктики [11], сконцентрировано более $96 \%$ платиновых металлов и более $90 \%$ никеля и кобальта; здесь добывается около $80 \%$ российского газа и $60 \%$ нефти [7].

Слабый уровень освоенности арктических территорий не позволяет достигнуть эффективного развития минерально-сырьевого потенциала региона простой аккумуляцией финансовых и производственных ресурсов - требуются вложения значительного объема инвестиций в инфраструктурное обустройство [9]. Анализ проектов по освоению расположенных в удаленных районах месторождений свидетельствует о том, что бо́льшая часть затрат приходится на создание общей инфраструктуры, нежели на строительство объектов, непосредственно предназначенных для добычи сырья. Такое соотношение затрат приводит к убыточности большинства проектов, в результате чего их реализация невозможна.

При реализации крупных сырьевых проектов бо́льшую часть работ выполняют подрядчики и поставщики, которыми выступают сервисные компании, научные и образовательные учреждения, предприятия транспорта и связи, лизинговые компании и т.д. [6]. Ввиду этого возникает необходимость моделирования гибких территориально-производственных систем в форме кластеров, которые позволят не только оптимизировать проектные издержки, но и сформировать инфраструктурный каркас для дальнейшего развития региона.

Методология. Целью данного исследования является оценка возможностей применения механизма кластеризации при освоении минерально-сырьевого потенциала Арктической зоны РФ. Для достижения поставленной цели были решены следующие задачи: анализ предпосылок формирования кластерных образований на основе ресурсной базы Арктических регионов, оценка внешних и внутренних эффектов потенциальных арктических сырьевых кластеров, анализ эффективности арктических проектов, реализуемых на принципах кластеризации. При решении данных задач применялись методы обобщения, систематизации, сравнительного и стоимостного анализа, методы инвестиционной оценки.

Обсуждение. Успешное освоение технологически сложных арктических месторождений предполагает создание технологически современной, конкурентоспособной промышленности. Предпосылки к формированию инновационно-промышленных кластеров на основе арктической сырьевой базы обусловлены следующими факторами:

1) высокая концентрация месторождений углеводородов и твердых полезных ископаемых на относительно небольших территориях;

2) присутствие в регионе крупнейших компаний минерально-сырьевого сектора, которые потенциально могут стать лидерами кластерных образований и определять долговременную стратегию региональной экономической системы;

3) заинтересованность государства в социально-экономическом развитии Арктической зоны;

4) значительная потребность в разработке научно-технических инноваций и импортозамещении при проведении геолого-разведочных работ, разработке месторождений и производстве готовой продукции с высокой добавленной стоимостью.

Основным ядром инновационного кластера минерально-сырьевой направленности является горнопромышленный комплекс, который представляет собой систему взаимосвязанных объектов хозяйственных единиц производственного назначения в рамках одного или нескольких месторождений полезных ископаемых, сконцентрированных на определенной территории и интегрированных определенными производственно-технологическими связями. Состав и направленность производств определяется потенциалом ресурсной и инфраструктурной базы конкретной территории, что является главной особенностью кластеров в минерально-сырьевом комплексе.

Таким образом, базовой единицей формирования арктических сырьевых кластеров является совокупность расположенных вблизи друг друга перспективных объектов недропользования, достаточно изученных и целесообразных для привлечения инвестиций. Такие кластеры будут являться опорными точками в пространственной организации региональной экономики, определяющими основные направления социально-экономического развития региона и выступающими в качестве драйвера для смежных отраслей. 
Инновационный подход к освоению минерально-сырьевого потенциала...

Таким образом, кластерная модель развития минерально-сырьевой базы Арктического региона является наиболее оптимальной. Обоснование потенциальных эффектов от создания кластеров на основе ресурсного потенциала Российской Арктики представлено в табл.1.

Таблица 1

Прогнозируемые эффекты создания инновационных сырьевых кластеров в Арктической зоне

\begin{tabular}{|c|c|c|}
\hline Категория эффекта & Значение для участников кластера & Значение для региона и государства \\
\hline $\begin{array}{l}\text { Производственная эффек- } \\
\text { тивность }\end{array}$ & $\begin{array}{l}\text { Экономия капитальных и операционных } \\
\text { проектных затрат } \\
\text { Повышение производительности труда за } \\
\text { счет внутренней конкуренции } \\
\text { Увеличение возможностей диверсификации } \\
\text { сбыта за счет развития транспортной ин- } \\
\text { фраструктуры } \\
\text { Снижение трансакционных издержек за } \\
\text { счет большого числа участников кластера } \\
\text { Возможности получения государственной } \\
\text { поддержки }\end{array}$ & $\begin{array}{l}\text { Рост ВРП и ВВП } \\
\text { Увеличение налогов и платежей в бюджеты } \\
\text { различного уровня } \\
\text { Укрепление позиций на внешнем и внутреннем } \\
\text { рынках } \\
\text { Снижение зависимости от импорта сырья и } \\
\text { продуктов его переработки } \\
\text { Рост рынка сервисных услуг } \\
\text { Реализация новых проектов на базе инфра- } \\
\text { структуры кластера }\end{array}$ \\
\hline $\begin{array}{l}\text { Инновационная эффектив- } \\
\text { ность }\end{array}$ & $\begin{array}{l}\text { Формирование инновационного окружения } \\
\text { и ускорение распространения инноваций } \\
\text { Увеличение инновационной активности за } \\
\text { счет внутренней конкуренции } \\
\text { Снижение издержек доступа к новым тех- } \\
\text { нологиям }\end{array}$ & $\begin{array}{l}\text { Импортозамещение технологий } \\
\text { Повышение инновационного потенциала ре- } \\
\text { гиона }\end{array}$ \\
\hline Социальная эффективность & $\begin{array}{l}\text { Улучшение условий труда за счет внедре- } \\
\text { ния передовых технологий } \\
\text { Развитый рынок труда }\end{array}$ & $\begin{array}{l}\text { Приток населения } \\
\text { Снижение безработицы } \\
\text { Сохранение местных квалифицированных кадров } \\
\text { Создание объектов инфраструктуры общего } \\
\text { назначения } \\
\text { Электрификация и газификация отдаленных } \\
\text { районов } \\
\text { Преимущества от социальной политики недро- } \\
\text { пользователей и прочих компаний-участников } \\
\text { кластера }\end{array}$ \\
\hline Эффекты глобализации & $\begin{array}{l}\text { Возможности привлечения зарубежных } \\
\text { партнеров: участие иностранных компаний } \\
\text { в финансировании, обмен технологиями и } \\
\text { опытом реализации сложных и высокорис- } \\
\text { кованных проектов }\end{array}$ & Развитие международного сотрудничества \\
\hline $\begin{array}{l}\text { Экологическая эффектив- } \\
\text { ность }\end{array}$ & $\begin{array}{l}\text { Минимизация негативного воздействия на } \\
\text { окружающую среду за счет инновационных } \\
\text { технологий организации производства и } \\
\text { проведения совместных природоохранных } \\
\text { мероприятий } \\
\text { Снижение штрафов и иных выплат, связан- } \\
\text { ных с нарушением экологических норм }\end{array}$ & $\begin{array}{l}\text { Сохранение экологического баланса, активное } \\
\text { внедрение технологий ресурсосбережения }\end{array}$ \\
\hline
\end{tabular}

В соответствии с утвержденной в 2014 г. государственной программой «Социальноэкономическое развитие Арктической зоны Российской Федерации на период до 2020 года и дальнейшую перспективу» освоение Арктики планируется через систему «опорных зон», в основе формирования которых был положен принцип административно-территориального деления. На настоящий момент Минэкономразвития выделено восемь опорных зон, что соответствует числу арктических субъектов РФ [7]. Каждая опорная зона рассматривается как территориальный мультипроект и аккумулирует совокупность разноотраслевых проектов. Такой механизм предполагает создание благоприятных условий для реализации крупных инвестиционных проектов в Арктике, интенсификацию судоходства по трассам Северного морского пути, системную модернизацию существующей инфраструктуры, что в совокупности окажет положительное влияние на развитие арктических субъектов России. 
Формирование опорных зон предусматривает широкое использование проектного подхода преимущественно бюджетного финансирования, что создает условия для решения различных социально-экономических задач. Учитывая планируемый характер взаимоувязки разноотраслевых проектов и мероприятий, реализация такой программы предполагает активное применение интеграционных форм для достижения сложных стратегических целей.

Значительный объем запасов и прогнозных ресурсов сырья в опорных зонах наряду с отсутствием инфраструктуры и высокой капиталоемкостью ее строительства в местах перспективной добычи открывает широкие возможности для формирования минерально-сырьевых центров, основанных на принципах кластеризации и позволяющих получить положительные эффекты (табл.2). Данный подход не только повысит инвестиционную привлекательность региона за счет увеличения рентабельности освоения минерально-сырьевого потенциала опорных зон, но и сформирует конструктивные взаимоотношения между различными участниками на основе баланса стратегических интересов в долгосрочной перспективе.

Сырьевой потенциал опорных зон

\begin{tabular}{|c|c|c|}
\hline Опорная зона & $\begin{array}{c}\text { Основные центры добычи } \\
\text { (существующие и перспективные) }\end{array}$ & Основные месторождения \\
\hline \multirow[t]{5}{*}{ Кольская } & $\begin{array}{l}\text { Шельфовые углеводородные } \\
\text { месторождения Баренцева моря }\end{array}$ & $\begin{array}{l}\text { Штокмановское, Мурманское, Лудловское, Ледовое, Северо- } \\
\text { Кильдинское }\end{array}$ \\
\hline & $\begin{array}{l}\text { Хибинская группа апатит- } \\
\text { нефелиновых месторождений }\end{array}$ & $\begin{array}{l}\text { Кукисвумчоррское, Юкспорское, Апатитовый цирк, Плато } \\
\text { Расвумчорр, Коашва, Ньорпахк, Куэльпор, Партомчорр, } \\
\text { Олений ручей }\end{array}$ \\
\hline & $\begin{array}{l}\text { Группа месторождений } \\
\text { сульфидных медно-никелевых руд }\end{array}$ & $\begin{array}{l}\text { Ждановское, Заполярное, Котсельваара, Семилетка, Быстринское, } \\
\text { Тундровое, Спутник, Верхнее }\end{array}$ \\
\hline & Оленегорский рудный район & $\begin{array}{l}\text { Оленегорское, } \\
\text { Кировогорское, им. Баумана, XV лет Октября, Комсомольское }\end{array}$ \\
\hline & Кольская провинция & Месторождения железных руд, хрома, РЗМ, фосфора \\
\hline Архангельская & $\begin{array}{l}\text { Центр добычи в архипелаге Новая } \\
\text { Земля }\end{array}$ & $\begin{array}{l}\text { Павловское месторождение свинцово-цинковых руд, } \\
\text { Приновоземельская группа месторождений углеводородов }\end{array}$ \\
\hline Ненецкая & $\begin{array}{l}\text { Месторождения углеводородов } \\
\text { Тимано-Печорской нефтегазонос- } \\
\text { ной провинции }\end{array}$ & $\begin{array}{l}\text { Приразломное, Кумжинское, Харьягинское, Ярегское, } \\
\text { месторождения Вала Гамбурцева }\end{array}$ \\
\hline Воркутинская & Печорский угольный бассейн & $\begin{array}{l}\text { Воркутинское, Интинское, Усинское, Юньягинское и } \\
\text { Варгашорское }\end{array}$ \\
\hline Ямало-Ненецкая & $\begin{array}{l}\text { Шельфовые и континентальные } \\
\text { месторождения углеводородов }\end{array}$ & $\begin{array}{l}\text { Харасавейское, Бованенковское, Тамбейская группа, } \\
\text { Крузенштернское, } \\
\text { Новопортовское, Мессояхская группа }\end{array}$ \\
\hline \multirow[t]{5}{*}{$\begin{array}{l}\text { Таймыро- } \\
\text { Туруханская }\end{array}$} & $\begin{array}{l}\text { Ванкорская группа углеводород- } \\
\text { ных месторождений }\end{array}$ & Ванкорское, Лодочное, Тагульское, Сузунское \\
\hline & $\begin{array}{l}\text { Усть-Енисейский центр нефтедо- } \\
\text { бычи }\end{array}$ & Пайяхское, Байкаловское \\
\hline & Хатангский центр нефтедобычи & Восточно-Таймырский лицензионный участок \\
\hline & Таймырский угольный бассейн & Черноярское, Пясинское, Крестьянское, Сырдасайское \\
\hline & $\begin{array}{l}\text { Месторождения сульфидных мед- } \\
\text { но-никелевых руд }\end{array}$ & Октябрьское, Талнахское, Норильск-1 \\
\hline \multirow[t]{4}{*}{ Северо-Якутская } & Кластер «Усть-Яна» & $\begin{array}{l}\text { Месторождение редкоземельных металлов Томтор, оловорудное } \\
\text { месторождение Депутатское, месторождения россыпного олова } \\
\text { ручей Тирехтях, Чурпунья, Одинокое }\end{array}$ \\
\hline & Анабарский центр добычи алмазов & Эбелях, Моргор \\
\hline & Центры добычи золота & Кючус, Хаптагай-Хая (+сурьма), Тамара-Тасс \\
\hline & Таймылырский кластер & Таймылырское месторождение угля \\
\hline \multirow[t]{2}{*}{ Чукотская } & $\begin{array}{l}\text { Беринговский каменноугольный } \\
\text { бассейн }\end{array}$ & Амаамское, Верхне-Алькатваамское, Бухта Угольная \\
\hline & $\begin{array}{l}\text { Центры добычи широкого ком- } \\
\text { плекса цветных и драгоценных } \\
\text { металлов }\end{array}$ & $\begin{array}{l}\text { Месторождения меди, никеля, висмута, ртути, олова, свинца, ура- } \\
\text { на, золота, платины, серебра }\end{array}$ \\
\hline
\end{tabular}


Инновационный подход к освоению минерально-сырьевого потенциала...

Российская экономика в настоящее время сильно зависит от нефтегазового сектора. Истощение ресурсов в традиционных нефтегазодобывающих центрах актуализирует развитие арктического углеводородного потенциала, который ввиду огромных запасов по праву считается ресурной базой XXIв. [15]. Так, по подсчетам Геологической службы США, в Арктике представлено более 13 \% извлекаемых общемировых запасов нефти и более 30 \% запасов газа [10].

В развитии нефтегазовых месторождений Арктической зоны большое значение имеют ямальские проекты. Доля Ямало-Ненецкого автономного округа в общем объеме инвестиций в основной капитал Арктического макрорегиона превышает $66 \%$, а в масштабах России Ямал входит в первую тройку по критерию отчислений в федеральный бюджет [4]. В числе наиболее приоритетных проектов, реализуемых в настоящий момент - «Новый порт», «Мессояха» и «Ямал СПГ», которые целесообразно рассматривать как самостоятельные минерально-сырьевые центры, аккумулирующие усилия российских и зарубежных нефтегазовых компаний, проектных институтов, научно-исследовательских центров, сервисных компаний, машиностроительных, судостроительных заводов и ряда других субъектов.

Центральным добывающим активом Новопортовского центра является одно из самых крупных по запасам на Ямале Новопортовское нефтегазоконденсатное месторождение, разработка которого до 2012 г. была невозможна ввиду отсутствия транспортной инфраструктуры и необходимых технологий. В перспективе к этому центру может быть подключено Ростовцевское месторождение, находящееся в данный момент в нераспределенном фонде недр [5].

Уникальность данного проекта обусловлена морским способом транспортировки сырья, поскольку традиционно ямальская нефть реализовывалась через трубопроводные системы. Ввиду этого ключевым стратегическим объектом проекта является первый арктический терминал на Ямале - Ворота Арктики, построенный в акватории Обской губы. Проектная мощность терминала составляет 8,5 млн т в год. Строительство данного терминала станет основным драйвером для развития шельфовых углеводородных месторождений Обско-Тазовской губы. На берегу Обской губы были также построены подводный и сухопутный нефтепроводы, резервуарный парк, насосные станции; каждый из этих объектов рассчитан на работу в экстремальных условиях Севера и соответствует всем экологическим требованиям.

Мессояхский центр включает в себя два месторождения - Восточно-Мессояхское и ЗападноМессояхское, открытые в 80-е годы. До 2016 г. разработке уникальных по величине запасов месторождений препятствовала транспортно-промышленная автономия района. В непосредственной близости от месторождений расположены перспективные лицензионные участки нераспределенного фонда недр, которые могут быть впоследствии также разработаны в рамках развития Мессояхского минерально-сырьевого центра. Синергия потенциальных ресурсов с существующими запасами по месторождению в совокупности с вводимыми в рамках проекта инфраструктурными мощностями позволит существенно повысить экономическую ценность актива.

Создание Мессояхского центра началось с освоения Восточно-Мессояхского месторождения, первая нефть с которого была отгружена в 2016 г. Импульсом к реализации проекта стало утверждение Правительством РФ «Программы комплексного освоения месторождений ЯНАО и севера Красноярского края до 2020 года», которая предполагала строительство ветки нефтепровода Заполярье - Пурпе, являющегося частью нефтепроводной системой Восточная Сибирь Тихий океан.

Уникальность проекта заключается в том, что в целях избежания растепления вечномерзлотных грунтов и минимизации рисков их просадки, обвалов, и, как следствие - аварий, все инфраструктурные объекты реализованы над поверхностью земли на сваях. В числе наиболее капиталоемких объектов - центральный пункт сбора и газотурбинная электростанция, работающая на природном и нефтяном газе.

Минерально-сырьевой центр «Ямал СПГ» на базе Южно-Тамбейского газоконденсатного месторождения направлен на развитие российской индустрии сжиженного природного газа (СПГ). Технология транспортировки и хранения природного газа в сжиженном состоянии становится актуальной тенденцией в мировом энергетическом секторе [2]. Несмотря на колоссальные запасы природного газа в России, индустрия СПГ только начинает развиваться, и в настоящее время в стране функционирует лишь один завод по производству СПГ - Сахалин-2. Проект «Ямал СПГ» позволит увеличить долю России на мировом рынке СПГ, что соответствует положениям Энергетической стратегии до 2035 г. [3]. 
Главной особенностью данного проекта и его существенным ограничением считается изначальное отсутствие транспортной и социальной инфраструктуры в регионе, поэтому для целей данного проекта был построен морской порт, аэропорт и вахтовый комплекс в пос. Сабетта, которые в долгосрочной перспективе могут выступить драйверами для реализации иных арктических проектов. Так, порт Сабетта будет использоваться не только для экспорта сжиженного природного газа, но и позволит транспортировать нефть, нефтепродукты, уголь и прочие виды сырья, что увеличит грузопоток Северного морского пути.

Рассматриваемые проекты являются экспортоориентированными, что обуславливает их значимость в развитии внешней торговли, диверсификации направлений сбыта и усилении позиций России на мировых рынках углеводородного сырья. Среди основных преимуществ от их реализации - создание дополнительного импульса для российской экономики в части загрузки имеющихся производственных мощностей предприятий машиностроения, металлургии, судостроения, а также развития наукоемких технологий для ведения работ в сложных условиях Крайнего Севера. В числе внешних позитивных эффектов - накопление опыта в области реализации сложных арктических проектов. Передовые технологии добычи, подготовки, транспортировки углеводородов, разработанные для целей проектов, формируют инновационный потенциал для дальнейшего освоения Арктической зоны РФ. Данные аспекты во многом определяют заинтересованность государства в реализации анализируемых проектов, в результате чего каждый из них получил значительный объем государственной поддержки в виде предоставления налоговых льгот, а в случае с «Ямал СПГ» также прямые госинвестиции в ряд инфраструктурных объектов.

На основании данных из открытых источников был проведен инвестиционный анализ проектов, который позволил сделать вывод о том, что, несмотря на высокую капиталоемкость и нестабильную ситуацию на рынках энергоресурсов, проекты создания арктических центров добычи углеводородов являются эффективными (табл.3). Расчет бюджетных поступлений от их реализации подтверждает значимость данных проектов в генерации налоговых потоков. Инфраструктурный потенциал, созданный на прежде неосвоенных территориях, открывает широкие возможности для вовлечения в разработку ранее нерентабельных месторождений углеводородов и развития ресурсной базы минерально-сырьевых центров.

Таблиия 3

Оценка эффективности проектов создания центров добычи

\begin{tabular}{|c|c|c|c|c|}
\hline \multirow[b]{2}{*}{ Категория эффективности } & \multirow[b]{2}{*}{ Показатель } & \multicolumn{3}{|c|}{ Проекты } \\
\hline & & $\begin{array}{c}\text { Восточно-Мессояхское } \\
\text { и Западно-Мессояхское } \\
\text { месторождения }\end{array}$ & $\begin{array}{l}\text { Новопортовское } \\
\text { месторождение }\end{array}$ & $\begin{array}{c}\text { Ямал СПГ } \\
\text { (включая разработку } \\
\text { Южно-Тамбейского } \\
\text { месторождения) }\end{array}$ \\
\hline \multirow{4}{*}{$\begin{array}{l}\text { Коммерческая эффек- } \\
\text { тивность }\end{array}$} & ЧДД, млн руб. & 15837 & 6338 & 119827 \\
\hline & ИД & 1,07 & 1,03 & 1,07 \\
\hline & Срок окупаемости, год & 17 & 20 & 23 \\
\hline & ВНД & $\begin{array}{c}17,43 \text { \% (при норме дис- } \\
\text { конта } 15 \% \text { ) }\end{array}$ & $\begin{array}{c}16,87 \% \text { (при норме } \\
\text { дисконта } 15 \% \text { ) }\end{array}$ & $\begin{array}{c}12,5 \% \text { (при норме } \\
\text { дисконта } 12 \% \text { ) }\end{array}$ \\
\hline \multirow[t]{2}{*}{$\begin{array}{l}\text { Бюджетная эффектив- } \\
\text { ность }\end{array}$} & $\begin{array}{c}\text { Региональный уровень, } \\
\text { млн руб. }\end{array}$ & 37915 & 40743 & 101172 \\
\hline & $\begin{array}{c}\text { Федеральный уровень, } \\
\text { млн руб. }\end{array}$ & 1831589 & 1459777 & 255223 \\
\hline
\end{tabular}

\section{Выводы}

На основании результатов исследования были сделаны следующие выводы:

1. Арктическая зона России представляет собой перспективный регион, ресурсный потенциал которого позволит не только обеспечить значительную часть внутренних и внешних потребностей в различных видах сырья и первичных энергоносителях, но и принесет большой экономический эффект для недропользователей и государства. 
Инновационный подход к освоению минерально-сырьевого потенциала...

2. Ключевой особенностью арктических минерально-сырьевых проектов является их ориентация на достижение не только коммерческих целей, но и на ускорение социально-экономического развития региона. Данный аспект обуславливает необходимость применения специфического подхода к организации взаимодействия между промышленностью, государством и финансовыми институтами, позволяющего учесть интересы каждого субъекта в долгосрочной перспективе.

3. Формирование кластерных образований на базе сырьевого потенциала Российской Арктики повышает эффективность реализации капиталоемких и технически сложных проектов, ускоряет развитие наукоемких технологий и способствует росту инвестиционной привлекательности региона.

4. Реализация арктических проектов «Новый порт», «Мессояха» и «Ямал СПГ» на принципах кластеризации доказала целесообразность взаимодействия государства и хозяйствующих субъектов: в процессе выполнения проектных работ были созданы условия для инновационного развития смежных отраслей, в регионе был сформирован высокотехнологичный инфраструктурный каркас, а на эксплуатационной стадии проектов ожидается выход на высокие показатели инвестиционной эффективности.

Благодарность. Исследование выполнено при финансовой поддержке РФФИ. Проект № 18-010-00734 «Разработка методологии технологического прогнозирования развития взаимосвязанных промышленных и соичильно-экономических систем при освоении углеводородных ресурсов Арктики».

\section{ЛИТЕРАТУРА}

1. Агафонов B.A. Региональные инновационные кластеры // Региональная экономика и управление: электронный научный журнал. 2015. Вып. 3 (43). С. 2-16.

2. Евсеева О.О. Особенности проектирования бизнес-моделей в индустрии сжиженного природного газа /О.О.Евсеева, А.Е.Череповицын // Государство и бизнес. Современные проблемы экономики: Материалы IX Международной научнопрактической конференции, 19-21 апреля 2017 / Северо-Западный институт управления РАНХиГС при Президенте РФ. СПб, 2017. С. 209-215.

3. Евсеева О.О. Перспективы российских проектов по сжижению природного газа и особенности их оценки / О.О.Евсеева, А.Е.Череповицын // Неделя науки СПбПУ: Материалы научного форума с международным участием / СанктПетербургский политехнический университет. СПб, 2016. С. 110-113.

4. Кобылкин Д. Арктика - это мощный драйвер экономики всей страны // Коммерсантъ. URL: http://proarctic.ru/05/12/2016/expert/24422 (дата обращения 08.11.2017).

5. Конторович А.Э. Нефть и газ Российской Арктики: история освоения в XX веке, ресурсы, стратегия на XXI век // Наука из первых рук. 2015. Вып. 1 (61). С. 46-65.

6. Ларичкин Ф.Д. Проблемы изучения и освоения минерально-сырьевых ресурсов Арктического региона / Ф.Д.Ларичкин, А.М.Фадеев, А.Е.Череповицын // Арктика: экология и экономика. 2012. Вып. 1 (5). С. 8-15.

7. Минерально-сырьевые центры как драйверы экономического развития Арктической зоны. URL: http://proarctic.ru/29/03/2017/resources/25915 (дата обращения 08.11.2017).

8. Формирование опорных зон в Арктике: методология и практика / О.О.Смирнова, С.А.Липина, Е.В.Кудряшова, Т.Ф.Крейденко, Ю.Н.Богданова // Арктика и Север. 2016. № 25. С. 148-157.

9. Carayannis E.G. Sustainable Development of the Russian Arctic zone energy shelf: the Role of the Quintuple Innovation Helix Model / E.G.Carayannis, A.E.Cherepovitsyn, A.A.Ilinova// Journal of the Knowledge Economy. 2017. Iss. 2 (8). P. $456-470$. DOI:10.1007/s13132-017-0478-9

10. Conley H.A. Arctic economics in the 21st century. The benefits and costs of cold / H.A.Conley, D.L.Pumphrey, T.M.Toland, M. David. Washington: CSIS, 2013. 67 p.

11. Glomsrod S. The Economy of the North. Oslo: Statistics Norway, 2008. 102 p.

12. Ilinova A.A. Sustainable development of the Arctic zone of the Russian Federation: ecological aspect / A.A.Ilinova, D.M.Dmitrieva // Biosciences Biotechnology Research Asia. 2016. Iss. 13(4). P. 2101-2106. DOI : 10.13005/bbra/2370

13. Porter M.E. Location, Competition, and Economic Development: Local Clusters in a Global Economy // Economic Development Quarterly. 2000. Iss.1 (14). P. 15-34. DOI: 10.1177/089124240001400105

14. Potter J. Clusters, Innovation and Entrepreneurship / J.Potter, G.Miranda. Paris: OECD Publishing, 2009. 233 p.

15. Sakhuja V. Asia in the Arctic. Narratives, Perspectives and Policies / V.Sakhuja, K.Narula. Singapore: Springer, 2016.143 p.

16. Solvell O. The Cluster Initiative Green book / O.Solvell, G.Lindqvist, C.Ketels. Stockholm: Ivory Tower, 2003. 93 p.

Aвторы: А.Е.Череповицын, д-р экон. наук, профессор, aecherepovitsyn@spmi.ru (Санкт-Петербургский горный университет, Санкт-Петербург, Россия), С.А.Липина, д-р экон. наук, руководитель отделения «Мировой океан и Арктика»заместитель председателя совета по изучению производительных сил, s.lipina@таil.rи (Всероссийская академия внешней торговли Минэкономразвития России, Москва, Россия), О.О.Евсеева, магистрант, olgaevs@yandex.ru (CанкmПетербургский горный университет, Санкт-Петербург, Россия.

Статья поступила в редакииюю 11.02.2018.

Статья принята к публикации 27.06.2018. 